\title{
Espacios fronterizos del sur sudamericano. Propuesta de un modelo conceptual para su estudio
}

\section{Bordering spaces in the South American south. Proposals for a conceptual model for their study}

Alejandro Benedetti*

Resumen

Se presenta un modelo conceptual para abordar el estudio geográfico comparado de los espacios fronterizos formados entre Estados nacionales. La sistematización empírica en la que se basa la propuesta se realiza en el ámbito del sur sudamericano, entendiendo por tal al área donde se diferenciaron, a lo largo de los siglos XIX y xx, los territorios de seis Estados nacionales: Argentina, Bolivia, Brasil, Chile, Paraguay y Uruguay. Este artículo apunta a renovar, desde la tradición geográfica crítica, los estudios sobre fronteras de la Argentina, a partir de una mirada relacional y multiescalar en la construcción de los territorios. El modelo aludido reconoce seis componentes principales para el estudio de los espacios fronterizos: diferenciación territorial, fronterización, territorios interiores, territorios exteriores, lugares de frontera y movilidades.

Palabras clave: espacio fronterizo, frontera, límite, territorio.

Recibido el 13 de noviembre de 2013. Aprobado el 27 de febrero de 2014.

\begin{abstract}
This is a conceptual model for the comparative geographical study of border areas formed between national states. The empirical systematization this proposal is based on has been carried out in southern South America, defined as the area where, during the nineteenth and twentieth centuries, the territories of six national states were differentiated: Argentina, Bolivia, Brazil, Chile, Paraguay and Uruguay. This article aims to renew the studies on Argentine borders, from a critical geographic tradition point of view and based on a relational and multiscalar aspect on the construction of territories. The model recognizes six main components for the study of border areas: territorial differentiation, frontierization, internal territories, external territories, border areas and mobilities.

Keywords: bordering spaces, border, boundary, territory.
\end{abstract}

* Doctor en geografía. Concejo Nacional de Investigaciones Científicas y Técnicas (Conicet)/Universidad de Buenos Aires. Correo electrónico: alejandrobenedetti@ conicet.gov.ar 


\section{Introducción}

El estudio de los límites y las fronteras fue basal en el desarrollo de la geopolítica clásica (Paasi, 2013). La primera sistematización importante fue Politische Geographie, de Friedrich Ratzel (1897), donde el autor desarrolla su teoría sobre la frontera como epidermis del Estado, y donde su expansión era vista como una clave de su fortaleza. Ratzel le otorgaba a las fronteras mayor relevancia frente a otros elementos de la organización territorial: en su libro, no destina ninguna sección a analizar la función de la capital en la fortaleza del Estado, mientras que dedica sólo unas páginas a la consideración de las divisiones subnacionales. En los ámbitos académicos europeos y norteamericanos, tras la Segunda Guerra Mundial, el interés de la geografía política por las fronteras tendió a desaparecer, recuperándose en la década de 1990, con la caída del muro de Berlín, la fragmentación y la formación de nuevos estados europeos, los conflictos en Medio Oriente, la integración de los países de la eurozona y la aceleración del proceso de globalización como telón de fondo (Newman y Paasi, 1998). De todas maneras, debió pasar tiempo para que la geopolítica crítica se abocara seriamente a producir nuevas teorizaciones sobre las fronteras (Paasi, 2013).

Las propuestas de la geopolítica clásica europea tuvieron gran influencia en los estudios sobre frontera de los países del sur sudamericano y tras la Segunda Guerra Mundial, lejos de desaparecer, mantuvieron su vigencia, sobre todo en su versión escolar (Quintero, 1999). Muchos geógrafos argentinos ofrecieron sus ideas organicistas y exaltadas sobre la frontera, recogiendo la tradición iniciada por Ratzel. Un ejemplo es Raúl Rey Balmaceda, quien condensó y ordenó la forma en que se describía tradicionalmente a las fronteras, con un discurso alegatorio y una asociación directa entre territorio y Estado. Este autor proponía lo siguiente: "Línea, en un caso; área, en el otro: he aquí la diferencia fundamental entre límite y frontera" (Rey, 1979, p. 27). Una de sus preocupaciones recurrentes, enraizada en el nacionalismo territorial, eran las "pérdidas territoriales" como consecuencia de las llamadas "cuestiones limítrofes", donde la Argentina era vista como víctima del expansionismo de los países vecinos (Cicasele, 2009). En esta tradición, las fronteras dividían dos actores monolíticos y ahistóricos: nuestro país y el país hermano o país vecino —en el caso de las versiones más amistosas-o, simplemente, entre Argentina y Chile en las visiones más belicosas 
(Quintero, 1999). Las fronteras eran consideradas como barreras o muros y, como tales, tendían a pensarse como áreas "vacías" de sociabilidad.

La geopolítica crítica argentina empezó a surgir en la década de 1990, en confrontación con la tradición nacionalista recién reseñada, pero le destinó un escaso interés al tema de los límites y las fronteras internacionales. Esto contrasta con la proliferación de estudios sobre espacios fronterizos, motorizada por los aportes de profesionales procedentes de la antropología y la historia (para ampliar: Benedetti, 2007; Benedetti y Salizzi, 2011). En dicha área de estudios se pueden señalar algunas tendencias: 1. la discusión teórico-metodológica sobre la frontera pocas veces se articula con una sobre el territorio; por ejemplo, cuando se plantea una definición de la frontera como realidad dinámica conservando una noción estática y esencialista del territorio; 2 . se tendió a una atomización en estudios de casos sobre regiones fronterizas o sobre pares de ciudades limítrofes específicas, por lo que se fue perdiendo de vista la escala nacional; 3. escasean los estudios comparativos y los intentos por encontrar patrones de organización de los espacios fronterizos; 4. dado el interés por distanciarse de los tradicionales abordajes geopolíticos, se procuró presentar a la frontera desde abordajes que no fueran Estadocéntricos, lo que llevó, en cierta forma, a una invisibilidad de la presencia estatal.

El objetivo principal de este artículo es presentar un modelo conceptual para el estudio de los espacios fronterizos (en adelante $\mathrm{EF}$ ), desde un abordaje geopolítico crítico. Este modelo surge de la observación y caracterización exhaustiva y comparada, todavía en curso, de los EF del sur sudamericano. El documento estructura a partir del reconocimiento de seis componentes principales, que se mencionarán en el siguiente apartado. El objetivo secundario es establecer algunas comparaciones generales sobre los patrones de organización de los referidos EF.

Se privilegiará la escala del territorio estatal nacional, prestando atención a los procesos comunes a todo el EF compartido por dos países, pero sin dejar de considerar la multiplicidad de escalas imbricadas.

\section{Puntos de partida teórico-metodológicos}

Este trabajo forma parte de un esfuerzo a mediano plazo por avanzar en el conocimiento sistemático de los espacios fronterizos que la Argentina 
mantiene con sus vecinos, en el contexto más amplio de Sudamérica. Algunas ideas fueron sugeridas en Benedetti y Salizzi (2011), Kralich, Benedetti y Salizzi (2012), y Benedetti y Laguado (2013).

En forma sintética, se sostiene que el concepto de frontera debe corresponderse con el de territorio. Se parte de considerar a la frontera como uno de los componentes fundamentales en la conformación de cualquier territorio institucionalizado, como aquellos formados por los Estados nacionales, las grandes regiones o las regiones que buscan escindirse del Estado en el que están incluidas. Estas entidades geohistóricas son construcciones sociales que se transforman de manera permanente a partir de las prácticas materiales y simbólicas de la sociedad (García, 2002). La propuesta de este documento se basa en aportes de las llamadas "geografías del poder" y de la "geografía regional político-cultural". La primera se nutre con los aportes de Raffestin (1980) y Sack (1986) y fue ampliamente desarrollada por la geografía brasileña (Lopes, 1995; Haesbaert, 2004; Cataia, 2007). Parte de considerar que una de las principales dificultades de la geopolítica clásica fue su reducción a una geografía del Estado nacional, considerado éste como la única fuente de poder y, por lo tanto, como agente en la construcción territorial. Otra clave es la crítica y revisión de los supuestos autoritarios sobre el poder. Por esta vía, se reformulan las vinculaciones entre espacio y poder, lo que le permite a Raffestin elaborar su geografía del poder bajo una concepción relacional y flexible (Lladó, 2005) que conllevó a una mayor flexibilidad de las escalas espacio-temporales involucradas en la pesquisa: las escalas no están definidas con antelación a la investigación sino, viceversa, son parte del problema de investigación. Así, la geografía política ya no se interesa sólo por los territorios de los Estados nacionales, o por los territorios permanentes, sino también por las territorialidades móviles, temporarias y de límites elásticos. La nueva geografía regional anglosajona también ha realizado significativas contribuciones a la conceptualización del territorio, nutriéndose de perspectivas humanistas y de las teorías del nacionalismo y la formación del Estado nacional de la historiografía inglesa del último periodo (Quintero, 2007). Afirmando que la forma nación tiene historicidad, y que no constituye una identidad colectiva previa ni necesaria a la formación y conservación de los Estados, que la identidad nacional no es ni necesaria ni previa a la formación y conservación de los Estados (Hobsbawm, 1990; Quintero, 2007), queda claro 
que tanto el territorio como las identidades territoriales son también construcciones históricas, procesos abiertos y contingentes. Esta perspectiva, por ejemplo a partir de los trabajos de Paasi (1986, 2003), suele interesarse por los espacios de escalas intermedias (provincias, regiones), pero ya no desde perspectivas esencialistas, como lo hacía la geografía regional clásica (Benedetti, 2009). Interesan, particularmente, las geografías internas, de la administración o de la organización del sistema democrático.

Los puntos de partida de este artículo se pueden sintetizar así: 1. se asume que es clave el concepto de territorialidad, entendido como una estrategia abiertamente desplegada por un sujeto social, espacial, cultural y temporalmente determinado para definir un área donde controlar recursos y personas. Dicha área es posible de ser denominada territorio; la diferencia operativa entre el territorio y cualquier otra categoría geográfica (espacio, región, lugar), es su asociación directa con el poder y la consideración del sujeto social que lo define; 2 . se sostiene una premisa multiescalar sobre la organización social del espacio: la escala del Estado nacional definiendo un territorio con límites precisos es una más, de igual importancia, en el juego de relaciones espaciales; 3. es menester prestar atención a las formas en que los grupos sociales se identifican y manifiestan sus solidaridades y contradicciones a través del espacio; 4 . se considera al territorio como una categoría heurística y no una realidad ontológica: se define a partir de las prácticas simbólicas y materiales de la sociedad; los territorios son entidades geohistóricas, procesos abiertos y contingentes. En definitiva, los territorios no "son", sino que "están siendo". Límites y fronteras, en tanto componentes del territorio, también deberían considerarse como entidades geohistóricas que se transforman de manera permanente a partir de las prácticas sociales.

En este escrito se usará espacio fronterizo como concepto clave, en lugar de frontera. Cada Estado nacional, en su proceso de construcción territorial, estableció su propia frontera nacional (en adelante sólo frontera) a partir del límite internacional, en un área que se extiende desde este límite hacia el interior y en una extensión que se buscó fuera estable: se originó a partir de acciones concretas realizadas por cada Estado, muchas veces como reflejo de lo realizado por el vecino, pero que se fue definiendo, en cada lugar, a partir del entramado singular de relaciones allí formado. A su vez, la frontera de un país surge, en gran medida, como espejo y reflejo de otra semejante en el país vecino. Por eso, el espacio fronterizo, 
a partir del límite internacional, adopta la forma de una díada (Cataia, 2007) o, en torno a un trifinio, de una tríada. En la génesis y pervivencia de las fronteras existe el interés de ambos Estados nacionales por controlar diferentes recursos y personas que eventualmente puedan cruzar por el límite compartido. Los vaivenes en las políticas de separación o de integración entre los Estados nacionales, las relaciones más o menos amistosas, la convivencia de grupos sociales locales y regionales con los semejantes del país vecino, las diferentes continuidades espaciales que vienen desde allende el límite internacional, fueron dejando sus marcas. Así, las dos o tres fronteras yuxtapuestas, con sus interacciones, unas veces amistosas y otras belicosas, constituyen otra entidad espacio-temporal, donde incluso puede germinar una identidad singular, que está en permanente tensión con una multiplicidad de territorialidades multiescalares: el espacio fronterizo. Los componentes básicos de un EF son el límite internacional y las dos o tres fronteras de los territorios linderos, dando origen a EF binacionales y a EF trinacionales.

El foco de este artículo son los EF binacionales que se formaron entre la Argentina y sus cinco países vecinos -Bolivia, Brasil, Chile, Paraguay y Uruguay-y, en menor proporción, los que se establecieron, a la vez, entre éstos entre sí. A este conjunto de países se denominará, genéricamente, región sur sudamericana, coincidente con lo que Rapoport (1998) designa como "Cono Sur". El modelo adoptado parte de considerar que los EF, como cualquier espacio, pueden pensarse como conjuntos indisociables, solidarios y contradictorios de objetos y acciones, que no deberían considerarse aisladamente y que forman el cuadro en el cual ocurre el devenir social (Santos, 1996). En términos metodológicos, a estos sistemas de objetos y acciones se les denominará componentes. Con base en una propuesta previa (Benedetti, 2003) y en el estudio que se está realizando en la región sur sudamericana (Benedetti y Laguado, 2013), aquí se propone que para estudiar la organización de los EF se pueden identificar seis componentes básicos (que se abordarán a continuación): 1. diferenciación territorial; 2 . fronterización; 3. territorios subnacionales o interiores; 4. territorios exteriores; 5 . lugares de frontera; y 6 . movilidades.

La identificación de estos componentes surge de la sistematización empírica generada al estudiar los EF de marras. La distinción de estos seis componentes principales y los diferentes subcomponentes es estrictamen- 
te analítica y no supone negar la existencia de otros posibles. Para ello, se adoptó una estrategia de lectura cartográfica, a partir del reconocimiento de diferentes capas de información. Cada capa remite a un componente y a sus subcomponentes, que ocurren en temporalidad y espacialidad multiescalares. Estos diferentes componentes y subcomponentes se abordarán de manera selectiva e intencionada. La superposición de estas diferentes capas permite ir reconociendo al espacio fronterizo al igual que si fuera un palimpsesto. Ciertamente, los subcomponentes que aquí se enumerarán, conceptualizarán y ejemplificarán no cubren todas las posibilidades. La elección de los mismos obedece a dos limitaciones: la extensión del artículo y el grado de avance de la investigación.

\section{Diferenciación territorial}

Al estudiar los EF no se puede dejar de tener en cuenta que allí se yuxtaponen dos o tres territorios Estado-nacionales. Un EF es, en realidad, un epifenómeno del proceso de construcción territorial de Estados modernos, linderos, simultáneos, aunque probablemente con ritmos diferentes pero que, mutuamente, buscaron diferenciarse. En esa construcción debieron resolverse cuestiones espaciales interiores, como la capitalidad o la conformación de la trama de divisiones político-administrativas. Simultáneamente, se establecieron relaciones con los países vecinos, tendientes a la separación de las porciones de la superficie terrestre que se pretende controlar con exclusividad y a establecer límites bilaterales. Todos los países han buscado imaginarse como comunidades territorialmente diferenciadas de sus vecinos (Anderson, 1991). Ese proceso, que ocurre tanto en el plano sociocultural como económico e institucional, puede denominarse como de "diferenciación territorial".

Analizar un proceso de diferenciación territorial supone prestar atención, simultáneamente, a la institucionalización (Paasi, 1986) de países linderos y, de manera recurrente, a diversas formas de intervención que realizan terceros. En el proceso de diferenciación territorial es posible identificar una etapa inicial, cuando emerge el espacio binacional, con múltiples cuestiones a resolver. Hay dos procesos fundamentales a considerar en la construcción de un EF: la distribución de áreas y la delimitación. 
La distribución de áreas entre dos países suele ser un proceso conflictivo. A veces se materializa mediante una guerra de "conquista" (como la incorporación de la región de Atacama a Chile, tras la Guerra del Pacífico) y otras mediante algún tipo de "canje" (como la cesión de derechos a la Puna de Atacama que realizó Bolivia a favor de Argentina, a cambio de que ésta dejara de reclamar derechos sobre Tarija). La formación de los Estados del sur sudamericano se inició en las primeras décadas del siglo XIX, a partir del debilitamiento y la crisis de las coronas ibéricas. Los nuevos países emergieron sobre la base de jurisdicciones internas que conformaban las posesiones coloniales: el Virreinato del Río de la Plata se fraccionó en cuatro Estados: Argentina, Uruguay, Paraguay y Bolivia; Chile es una herencia de la capitanía homónima; Brasil nació de las extintas posesiones portuguesas, que lograron mantenerse unificadas (Ansaldi y Giordano, 2012). El esfuerzo inicial de todos los primeros gobiernos independentistas fue legitimar y asegurar la adscripción a ciertas heredades de la administración colonial, en conflictivas relaciones internas y externas - tanto con los vecinos como con las potencias coloniales europeas. Desde entonces, se fueron ensayando diferentes ensambles territoriales, en una sucesión de conflictos militares, que finalmente en la segunda mitad de ese siglo permitió la consolidación de seis soberanías territoriales con continuidad hasta el presente. Una vez formado el núcleo original sobre el que se forjaron estas repúblicas, fue posible el avance de las fronteras hacia terrenos todavía controlados por sociedades originarias del continente, la conquista de tierras malamente controladas por otros países o la usurpación de regiones en momentos en que el vecino se encontraba debilitado.

La Patagonia, el Desierto y Puna de Atacama, el Pantanal, el Gran Chaco, las Misiones y el Acre fueron regiones disputadas por estos seis países durante el siglo xix. En muchos casos se trataba de EF que los nacientes Estados nacionales mantenían con diferentes naciones indígenas: el objetivo fue desactivarlos. En ese momento se suscitaron episodios cruentos, padecidos en gran medida por las sociedades originarias, para dirimir rivalidades y revalidar hegemonías en el acceso a los mares, la navegabilidad de los ríos de la cuenca del Plata y para abarcar la mayor extensión posible. Estas disputas aceleraron los procesos de consolidación estatal y, por tanto, de diferenciación territorial, constituyéndose en pasos 
previos a las delimitaciones, que generalmente habían sido postergadas. Durante el siglo xx no se registraron conflictos bélicos entre estos seis países (algo raro si se compara con lo que ocurrió en otras grandes regiones continentales del planeta), a excepción del que Bolivia y el Paraguay tuvieron en la década de 1930 por el control del Chaco Boreal (Domínguez, 2003).

La fijación del límite es clave en la diferenciación territorial. No se trata de un acto temporalmente fijo, sino de diferentes cursos de acciones, aquí denominado proceso de delimitación, definido éste como el conjunto de operaciones que realizan ambos países, a veces con la participación de terceros, tendientes a establecer y mantener el límite interestatal en toda su extensión —entre: dos trifinios/un trifinio y el mar/entre dos mares, dependiendo de la configuración geofísica sobre la que se organicen los territorios-, tanto en los documentos como en el terreno. Se pueden reconocer, al menos, seis tipos de acciones: 1. redacción y suscripción de tratados de paz (vía bélica) y/o de amistad (vía diplomática), lo que supone el mutuo reconocimiento como sujetos de derecho internacional, que suelen incluir consideraciones sobre soberanía territorial, comercio y navegabilidad; 2. suscripción de documentos, para explicitar los criterios generales por dónde trazar el límite (tratados, acuerdos, protocolos), con las correspondientes refrendas legislativas; 3. ajustes de criterios, requeridos generalmente por la imposibilidad técnica de implementar los términos acordados, con redacción de documentos suplementarios; 4. demarcación en el terreno, a cargo de peritos, y producción cartográfica alegatoria, que es la puesta en escena del sistema de información limítrofe: se colocan hitos, mojones, boyas, carteles, muros y otras marcas para ser vistas por propios y ajenos; 5. mantenimiento y ajuste del número de marcas, generalmente a cargo de comisiones mixtas específicas y 6. control de la producción cartográfica, donde se representen las áreas y los límites políticos del país, a cargo de institutos o servicios geográficos, civiles o militares.

La definición del mapa político del sur sudamericano requirió de 10 procesos de delimitación entre los seis países, dando como resultado una longitud de límites de casi 17 mil kilómetros (véase cuadro 1). Dichos procesos se iniciaron de cuatro formas: 1. por mutuo acuerdo, en relaciones más o menos amistosas; 2. con mediación diplomática, en un contexto posbélico o de guerra armada; 3. mediación después de una guerra; y 4. resolución 
diplomática acelerada por un conflicto militar con un tercer país. La manera en que este proceso se haya iniciado suele permanecer en la esencia del EF y, a posteriori, actualizarse en las relaciones de vecindad (siendo el caso boliviano-chileno el más evidente). En la definición de criterios para el trazado de límites se privilegiaron las formas hidrográficas y orográficas. Los ríos de la cuenca del Plata dieron nombre y sirvieron como base para el trazado del límite a tres repúblicas: Uruguay (en el río homónimo con la Argentina), Paraguay (en el río de igual nombre con Brasil y Argentina) y Argentina (cuyo nombre deriva del Río de la Plata, por argentino, plateado, que sirve de límite con Uruguay). Las altas cumbres de la cordillera de los Andes fueron una referencia para los límites de Chile con Argentina y Bolivia. Ningún límite responde a criterios culturales pretéritos, a diferencia de lo que ocurrió en Europa o Asia (Foucher, 1988), a excepción tal vez del límite hispano-lusitano en el río Uruguay que se mantuvo entre la Argentina y Brasil (véase cuadro 1).

En uno o en ambos extremos del límite trazado entre dos países, además, se encuentra un punto donde confluyen sendas jurisdicciones con la de un tercer Estado: los tripartitos o trifinios. En el sur de Sudamérica hay cinco trifinios, más otros dos con el Perú, que en su mayoría se encuentran escasamente poblados, convirtiéndose en espacios muy apreciados para las movilidades ilegales (González, 2009). En el trifinio formado entre Argentina, Brasil y Uruguay existe una de las mayores conurbaciones transfronterizas del subcontinente. A esta región fronteriza y urbanizada se le denomina "Triple Frontera".

\section{Fronterización}

En el contexto de los Estados nacionales, y especialmente con el desarrollo de los discursos geopolíticos nacionalistas que tuvieron gran proyección en el sur de Sudamérica durante las décadas centrales del siglo xx, la frontera nacional ha tendido a concebirse como un espacio uniforme, que bordea toda la periferia del territorio, adyacente al límite internacional. Lo anterior se debe a que los Estados nacionales, a lo largo de su proceso de organización, buscaron que sus fronteras coincidiesen en toda su extensión con los límites internacionales (Machado, 1990). Con fronterización, 
Estudios Fronterizos, nueva época, vol. 15, núm. 29, enero-junio de 2014

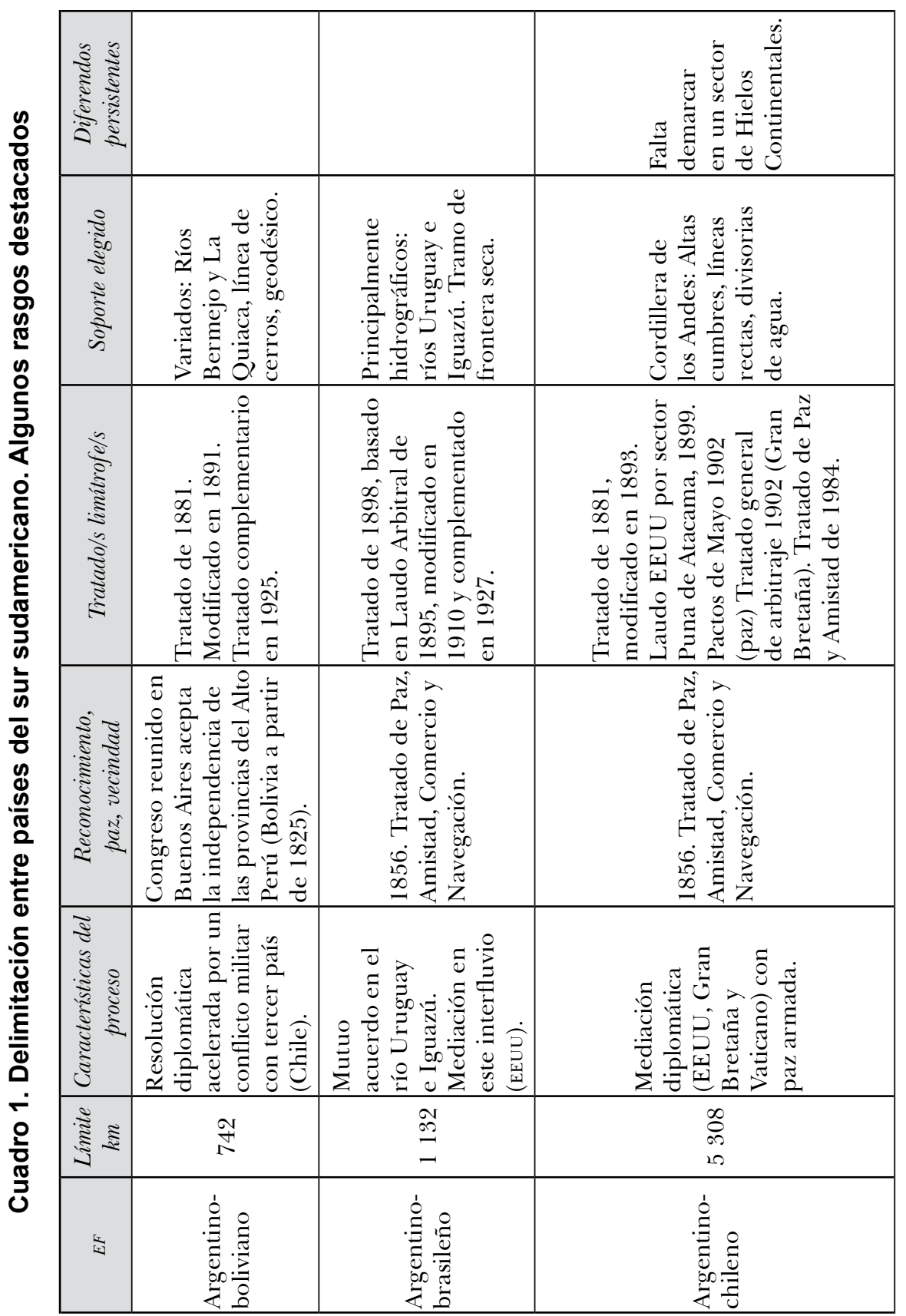




\begin{tabular}{|c|c|c|c|}
\hline & & 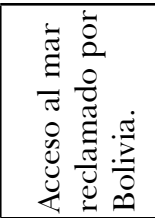 & \\
\hline 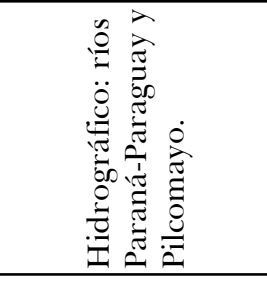 & 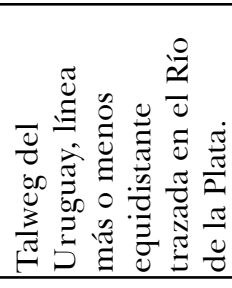 & 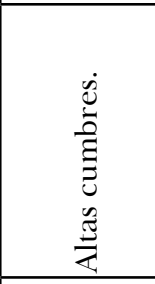 & 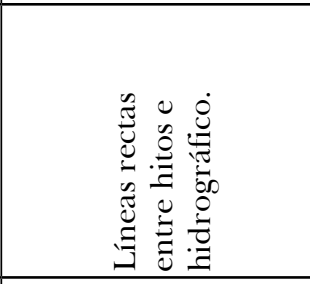 \\
\hline 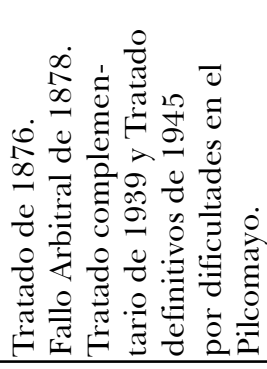 & 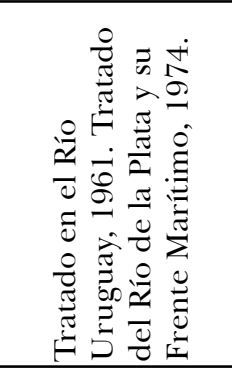 & 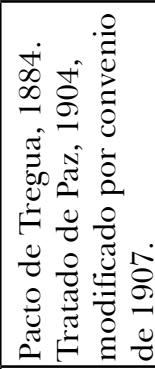 & 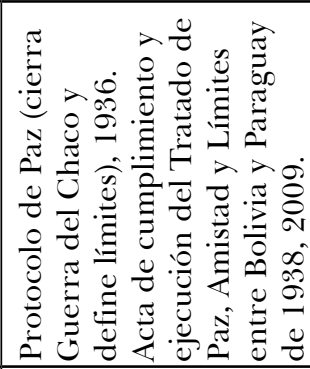 \\
\hline 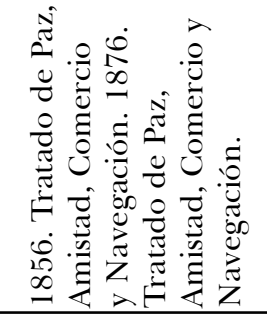 & 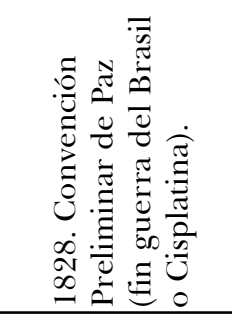 & 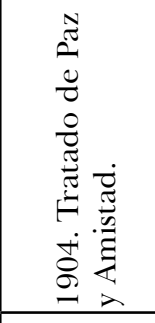 & $\begin{array}{l}0 \\
0 \\
0 \\
0 \\
0 \\
0 \\
0 \\
0 \\
0 \\
0 \\
0 \\
0 \\
0\end{array}$ \\
\hline 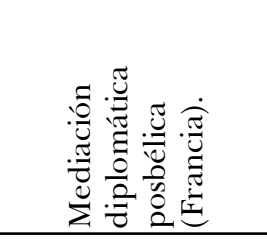 & 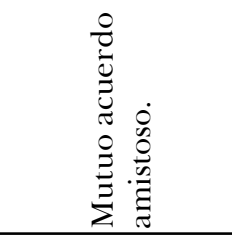 & 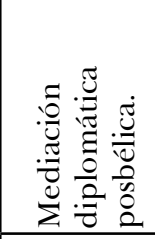 & 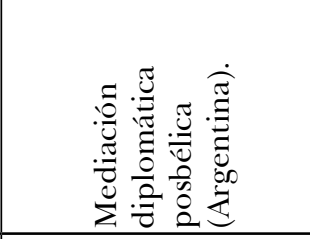 \\
\hline $\begin{array}{l}8 \\
0 \\
-1\end{array}$ & $\stackrel{2}{\circ}$ & $\underset{\infty}{0}$ & 10 \\
\hline 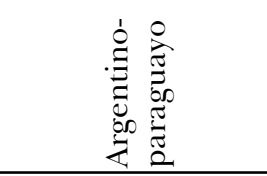 & 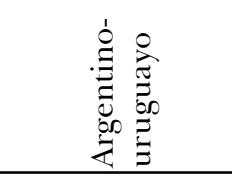 & 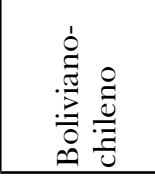 & 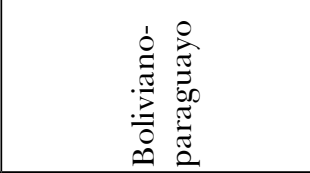 \\
\hline
\end{tabular}


Estudios Fronterizos, nueva época, vol. 15, núm. 29, enero-junio de 2014

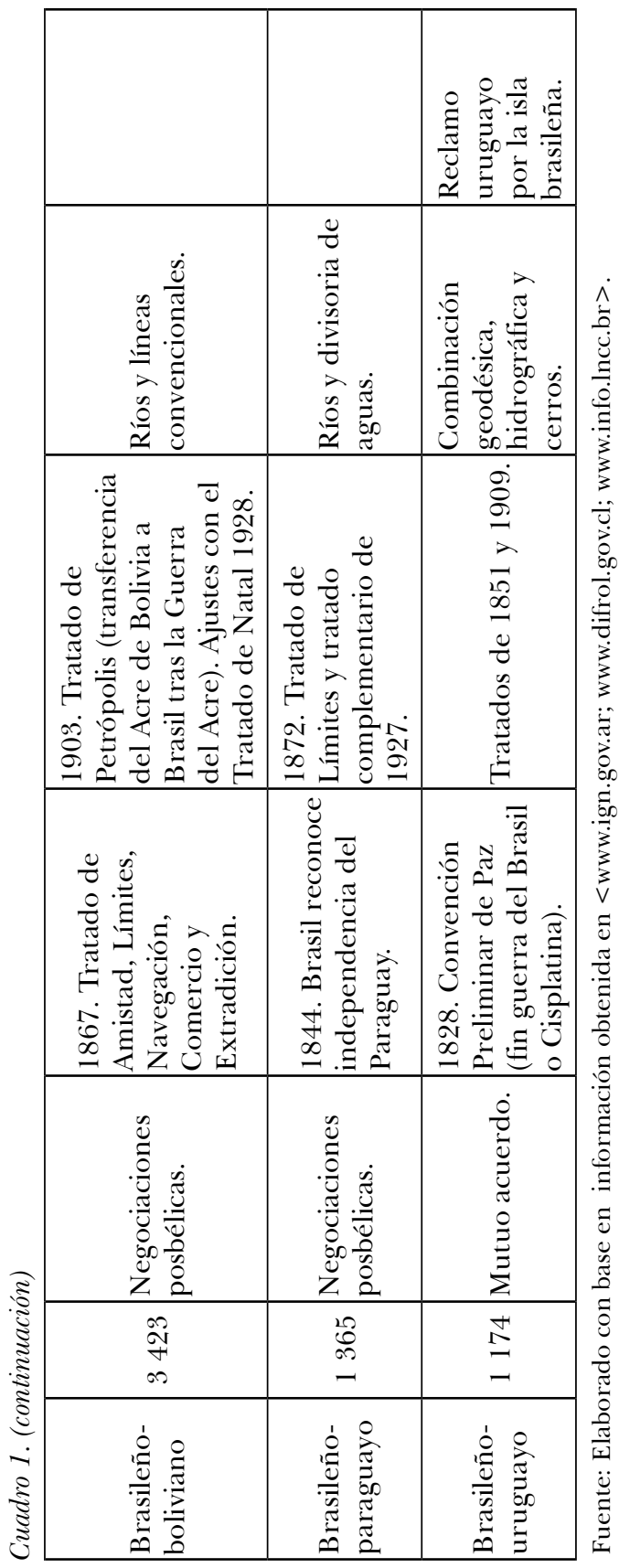


en sintonía con lo propuesto por Grimson (2003), se está subrayando el carácter contingente y procesual de las fronteras, al igual que el territorio del que son parte. El ejercicio del poder a través del espacio siempre implica la manipulación de la oposición entre continuidad y discontinuidad (Cataia, 2007), y la frontera, con todos sus elementos, es un dispositivo que se va estableciendo con tal propósito. En otros términos, fronterización designa al conjunto de objetos y acciones que el poder central va estableciendo, generalmente cerca del límite pero no inevitablemente, con la intención de controlar la accesibilidad. Es una realidad dinámica pero que, de todas formas, a través de diferentes elementos, va configurando ciertas rugosidades (Santos, 1996).

Límites y frontera aquí se tratan como entidades diferentes: cruzar el límite internacional no debe confundirse con cruzar la frontera; cruzando el límite todavía se está en un espacio fronterizo. El límite internacional es un dispositivo lineal, producto del esfuerzo por definir con la mayor precisión posible el área que se quiere controlar para un "nosotros", en oposición a un "otro/s" (Paasi, 2013). La frontera, de implantación tanto puntual (puestos de control) como por áreas (zonas fronterizas), se forma por los dispositivos políticos, culturales y económicos, generalmente puestos sobre el límite, allí en el frente, para efectivizar el control ante situaciones actuales o potenciales de egreso/ingreso al territorio: es un filtro para lo que pueda moverse a través del límite, según un sistema de normas e intereses, pero también de lo que pretende localizarse en sus inmediaciones, siguiendo determinados principios de seguridad nacional.

Límites y fronteras (nacionales o de cualquier tipo) son categorías específicas e interrelacionadas. Asimismo, aun cuando su localización pueda no cambiar, son entidades que están siendo permanentemente, a partir de diferentes prácticas sociales. La delimitación es el proceso a través del cual se establece, mantiene y transforma la localización, trazado, señalización, funciones y sentidos asociados al límite interestatal. De la misma manera, la fronterización es el proceso mediante el cual cada Estado establece, mantiene y transforma la localización, señalización, extensión, funciones y sentidos asociados a la frontera.

En el sur sudamericano las fronteras no se establecieron, inevitablemente, en forma conjunta con el límite. En general, ambos procesos tienen cronologías dispares: muchos controles aduaneros se establecieron 
cuando todavía el límite no estaba acordado y, viceversa, muchos lugares de fronteras se establecieron largo tiempo después de la delimitación. En algunos EF no existió, hasta bien avanzado el siglo xx, una presencia efectiva de los Estados nacionales, como es el caso del boliviano-paraguayo, quienes recién después de la Guerra del Chaco comenzaron el proceso de fronterización (Vázquez, 2009). Incluso Argentina y Chile, con una exitosa historia expansionista, comenzaron a tener un más férreo control fronterizo hacia las primeras décadas del siglo xx, en un intento por consolidar sendos mercados internos de producción y de trabajo. Durante los siglos XIX y xx la política cordillerana fue ambivalente, con cierres y aperturas del EF (Lacoste, 2004). En el extremo norte de este EF los controles comenzaron a ser efectivos hacia 1970, a través de puestos móviles, y recién en la década de 2000 se establecieron los primeros puestos fijos junto al límite del lado argentino, en los pasos de Jama y de Sico (Benedetti y Laguado, 2013).

La fronterización incluye al menos tres subcomponentes, que aquí se denominarán distritos, pasos y puestos.

Por distritos fronterizos (véase cuadro 2) se alude, en forma genérica, a las divisiones del territorio nacional establecidas para ejecutar acciones tales como seguridad, defensa, expropiación de tierras, desarrollo, urbanización, planificación de caminos, nacionalización cultural, sanidad y protección de recursos estratégicos. En general, se trata de fajas paralelas al límite, con extensiones variables, denominadas zona, franja, sector, región. También se institucionalizaron sectores puntuales, como las áreas de frontera de la Argentina, para asegurar el control de recursos considerados estratégicos ante hipótesis de conflicto.

Para permitir el cruce legal de objetos y personas a través del límite, los países han convenido habilitar diferentes puntos, llamados, genéricamente, pasos fronterizos. Suelen representarse como las "puertas" de entrada/ salida del país. Si bien son numerosos los pasos existentes entre los países en cuestión, no todos cuentan con las mismas facilidades para el cruce. En el caso argentino-chileno existen infinidad de valles y desfiladeros pero, en el intento por controlar la accesibilidad al espacio cordillerano, ambos países fueron organizando redes que privilegian la circulación por algunos de ellos. Existe un total de 42 pasos fronterizos acordados entre ambos países, pero sólo algunos fueron provistos de buenos caminos. Cinco de 


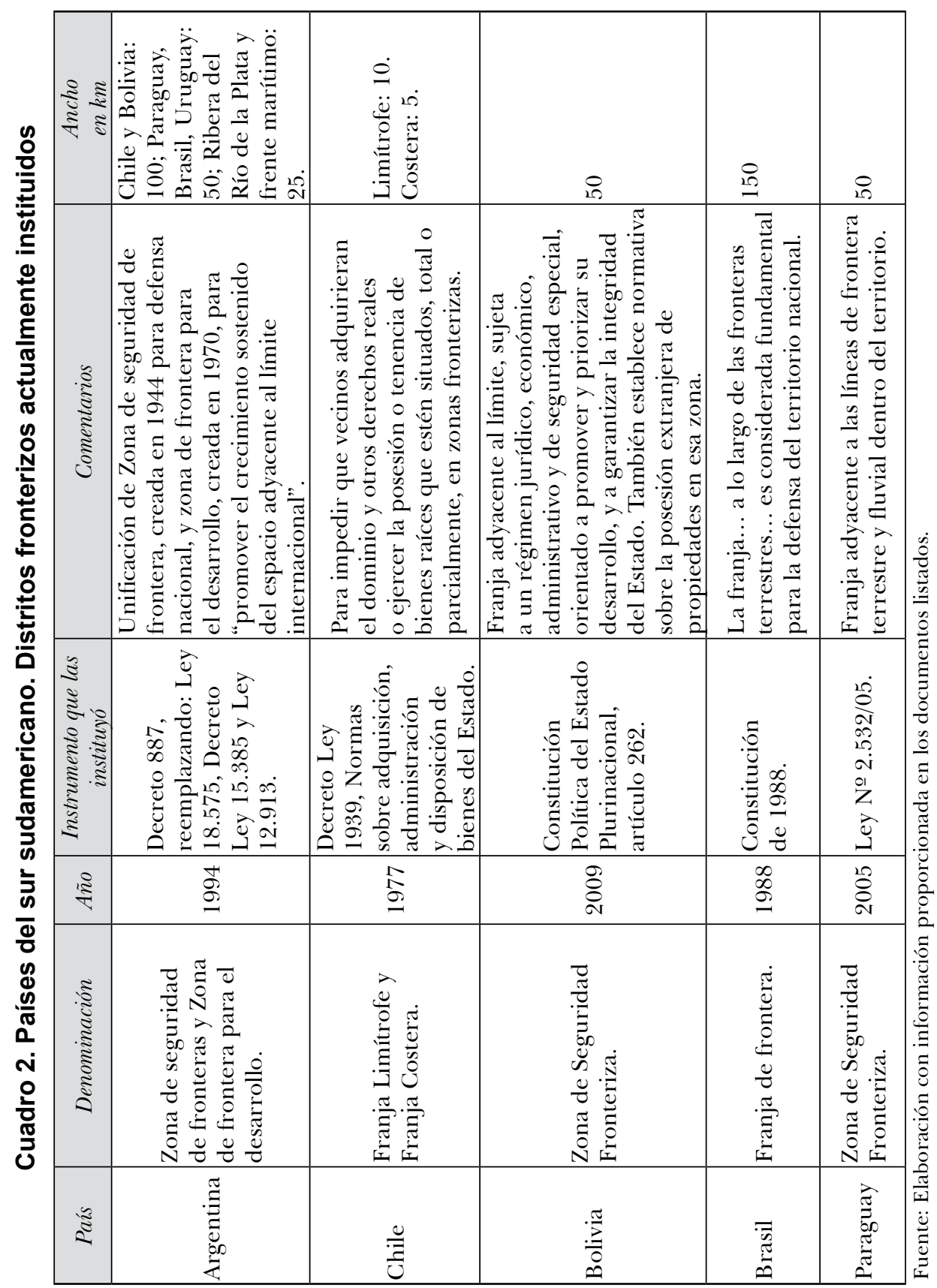


esos pasos fueron jerarquizados para la circulación a escala continental mediante los llamados "ejes de integración y desarrollo" —antes conocidos como "corredores bioceánicos" - que desde la década de 2000 son promovidos por la Iniciativa para la Integración Regional Suramericana (IIRSA) (Benedetti y Laguado, 2013).

Los pasos pueden estar habilitados específicamente para un tipo de operatoria: tráfico vecinal fronterizo (algunos pasos fluviales en la provincia argentina de Misiones con Brasil); turismo (paso Las Leñas entre Argentina y Chile); rogativas indígenas (en la provincia argentina de Neuquén con Chile); trashumancia (en la zona montañosa de la provincia argentina de San Juan con Chile); circulación de personal de empresas que operan gasoductos, oleoductos y electroductos o de empresas mineras binacionales (en el sur del EF argentino-chileno). Los pasos más importantes de la región, empero, están habilitados para todas o varias de esas opciones, incluyendo todas las categorías migratorias (permanente, temporal) y todas las operatorias aduaneras (tráfico vecinal fronterizo, régimen de equipajes, despacho de pasajeros y cargas). Así, los pasos permiten una diversidad de condiciones de accesibilidad, generando discontinuidades a lo largo del distrito fronterizo.

Considerando los casi 17 mil kilómetros de límites entre los países del sur sudamericano, la IIRSA (2002) identificó la existencia de 81 pasos legales, lo que representa una media de un paso cada $209 \mathrm{~km}$. Casi la mitad de esos pasos se encuentran en el EF argentino-chileno (véase cuadro 3).

Por otro lado, en el ámbito de los Estados se crearon diferentes dependencias del gobierno y de la administración pública avocadas directamente a controlar el ingreso/egreso de bienes y personas, o su permanencia y localización en los distritos fronterizos. Los funcionarios y empleados de estas dependencias no se encuentran en cualquier sitio, sino en algunos específicos: los puestos de control. Algunos son fijos, establecidos en edificios especialmente construidos para ese fin, sobre el paso mismo o en sus inmediaciones, donde se localizan las autoridades policiales, migratorias, aduaneras y sanitarias (véase cuadro 4). En el caso chileno se les denomina complejos fronterizos y a veces se ocupan de controlar más de un paso, como el de San Pedro de Atacama, con jurisdicción en los de Sico, Jama (con Argentina) e Hito del Cajón (con Bolivia). Se diferencian, además, pasos con controles "dobles", es decir, uno en cada frontera, o "integrados", 
Cuadro 3. Espacios fronterizos binacionales. Extensión de los límites internacionales, pasos fronterizos legales y distancia media entre pasos

\begin{tabular}{|l|r|r|r|}
\hline \multicolumn{1}{|c|}{ EF } & $\begin{array}{c}\text { Extensión límite } \\
\text { Km }^{2}\end{array}$ & \multicolumn{1}{c|}{$\begin{array}{c}\text { Cantidad } \\
\text { de pasos }\end{array}$} & $\begin{array}{c}\text { Distancia media } \\
\text { entre pasos }\end{array}$ \\
\hline Argentina-Bolivia & 742 & 3 & 247 \\
\hline Argentina-Brasil & 1132 & 15 & 75 \\
\hline Argentina-Chile & 5308 & 38 & 140 \\
\hline Argentina-Paraguay & 1699 & 8 & 212 \\
\hline Argentina-Uruguay & 495 & 3 & 165 \\
\hline Bolivia-Brasil & 3423 & 4 & 856 \\
\hline Bolivia-Chile & 860 & 1 & 860 \\
\hline Bolivia-Paraguay & 750 & - & 455 \\
\hline Brasil-Paraguay & 1365 & 3 & 196 \\
\hline Brasil-Uruguay & 1178 & 6 & 209 \\
\hline Total & 16952 & 81 & \\
\hline
\end{tabular}

Fuente: Elaboración con información publicada en IIRSA 2002, Instituto Geográfico Nacional (Argentina) y cálculos propios.

ubicados en una u otra de las fronteras, estos últimos como parte de las iniciativas del Mercado Común del Sur (Mercosur). En el EF argentinouruguayo los tres pasos viales tienen controles integrados, dos ubicados del lado uruguayo y uno del argentino. La mayoría de los pasos en el EF argentino-chileno mantiene controles dobles. Cada país, además, mantiene puestos de control móviles: patrullas ubicadas a diferentes distancias del límite, generalmente en encrucijadas que se conectan con pasos no habilitados.

Distritos, pasos y puestos de control —fijos y móviles - son los componentes básicos del complejo fronterizo nacional, que hacen efectiva la presencia institucional del Estado en las proximidades de los límites acordados con los vecinos. La suma de ambos complejos da origen a un complejo 


\section{Cuadro 4. Países del sur sudamericano. Principales dependencias de la administración pública con funciones fronterizas}

\begin{tabular}{|c|c|c|c|c|}
\hline País & Seguridad & Migración & Aduana & Controles sanitarios \\
\hline Argentina & $\begin{array}{l}\text { Gendarmería } \\
\text { Nacional, } \\
\text { Prefectura } \\
\text { Nacional, Policía } \\
\text { Federal Argentina. }\end{array}$ & $\begin{array}{l}\text { Dirección } \\
\text { Nacional } \\
\text { de Migración. }\end{array}$ & $\begin{array}{l}\text { Dirección } \\
\text { General } \\
\text { de Aduana. }\end{array}$ & $\begin{array}{l}\text { Servicio Nacional } \\
\text { de Sanidad } \\
\text { Agropecuaria. }\end{array}$ \\
\hline Bolivia & $\begin{array}{l}\text { Policía Nacional, } \\
\text { división Policía } \\
\text { Fronteriza. }\end{array}$ & $\begin{array}{l}\text { Dirección General } \\
\text { de Migraciones. }\end{array}$ & $\begin{array}{l}\text { Aduana } \\
\text { Nacional } \\
\text { de Bolivia. }\end{array}$ & $\begin{array}{l}\text { Servicio Nacional } \\
\text { de Sanidad } \\
\text { Agropecuaria } \\
\text { e Inocuidad } \\
\text { Alimentaria. }\end{array}$ \\
\hline Brasil & $\begin{array}{l}\text { Policía Federal, } \\
\text { Policía Militar. }\end{array}$ & Policía Federal. & Receita Federal. & $\begin{array}{l}\text { Agência Nacional } \\
\text { de Vigilância } \\
\text { Sanitária. }\end{array}$ \\
\hline Chile & $\begin{array}{l}\text { Carabineros de } \\
\text { Chile y Policía de } \\
\text { Investigaciones } \\
\text { de Chile, Jefatura } \\
\text { Extranjería. }\end{array}$ & $\begin{array}{l}\text { Departamento } \\
\text { de Extranjería } \\
\text { y Migraciones. }\end{array}$ & $\begin{array}{l}\text { Servicio Nacional } \\
\text { de Aduanas. }\end{array}$ & $\begin{array}{l}\text { Servicio Agrícola } \\
\text { y Ganadero. }\end{array}$ \\
\hline Paraguay & Policía Nacional. & $\begin{array}{l}\text { Dirección } \\
\text { Nacional } \\
\text { Migraciones. }\end{array}$ & $\begin{array}{l}\text { Dirección } \\
\text { Nacional de } \\
\text { Aduanas. }\end{array}$ & - \\
\hline Uruguay & $\begin{array}{l}\text { Prefectura } \\
\text { Nacional Naval. }\end{array}$ & $\begin{array}{l}\text { Dirección } \\
\text { Nacional de } \\
\text { Migración. }\end{array}$ & $\begin{array}{l}\text { Dirección } \\
\text { Nacional de } \\
\text { Aduanas. }\end{array}$ & $\begin{array}{l}\text { Dirección General } \\
\text { de Servicios } \\
\text { Agrícolas y } \\
\text { Dirección General } \\
\text { de Servicios } \\
\text { Ganaderos. }\end{array}$ \\
\hline
\end{tabular}

Fuente: Elaboración propia.

fronterizo binacional o, en un trifinio, a uno de triple frontera. Ésta es una de las escalas que participan en la conformación de los EF, a veces la más importante, pero no siempre, y remite a la presencia estatal. 


\section{Territorios subnacionales}

Los procesos de delimitación y fronterización no sólo participan en la configuración del territorio estatal nacional: también interfieren con otros, de escala inferior, y que pueden ser, grosso modo, gubernamentales, administrativos, productivos o culturales.

Regiones (Chile), Departamentos (Bolivia, Paraguay, Uruguay), Provincias (Argentina) y Estados (Brasil) son territorios de gobierno de primer orden presentes en los EF del sur sudamericano. Lo mismo ocurre con la multiplicidad de municipios, abarcados total o parcialmente por algún distrito fronterizo. Las autoridades de estos territorios suelen realizar diferentes gestiones con otras entidades subnacionales de países vecinos, en las llamadas "relaciones paradiplomáticas" (Ferrero, 2006). Un ejemplo significativo es la Alianza Estratégica Aymaras Sin Fonteras, en el espacio trinacional integrado por municipios rurales de Bolivia, Chile y el Perú, que surgió por el empoderamiento de los pueblos indígenas de identidad aymara ante la falta de acción de los gobiernos centrales (Rouvière, 2009).

Estos territorios, ubicados a uno y otro lado del límite internacional, en ocasiones tienen diferentes grados de autonomía y márgenes de negociación. En el EF argentino-chileno, las divisiones de primer orden, que en una primera comparación de los mapas políticos de ambos países pueden parecer equivalentes, tienen sus diferencias: del lado de la Argentina, país federal desde su génesis, se encuentran 11 provincias, que son estados subnacionales autónomos; en el lado chileno, con tradición unitaria, se encuentran 13 regiones. Si bien este país realizó un proceso de descentralización administrativa, las regiones no tienen autonomía política. Estas diferencias son un tipo de discontinuidad en el EF, en sentido transversal al límite internacional.

Los territorios de la administración pública son creados por los Estados para atender infinidad de asuntos, extendiéndose por todo el interior, alcanzando las fronteras. Algunas dependencias tienen una injerencia directa en las relaciones bilaterales, como las aduanas. Muchas otras, tal vez la mayoría, no tienen que ver estrictamente con esos asuntos, como las entidades de previsión social o las bancarias. De todas maneras, muchas veces su presencia puede ser más notoria en las fronteras que en zonas 
circunvecinas. En la Argentina, por caso, el Banco Nación fue un importante agente en la consolidación de muchas ciudades de frontera, alejadas de los grandes centros poblados o capitales de provincia. Más importantes todavía, fueron las "escuelas de frontera", destinadas a la afirmación de la identidad nacional en los bordes de los países. Las políticas de integración promovidas en la última década, de todas formas, están propiciando escuelas con otro perfil. Eso se visualiza en relación con la lengua. La escuela tenía el papel de reforzar y promover el uso de la lengua nacional y corregir las "hablas incorrectas" que se suscitan en los EF. Promovido por las sociedades locales, en el EF brasileño-uruguayo se han implementado políticas de educación bilingüe (Brovetto, 2010).

Una institución emblemática en el proceso de consolidación de la presencia estatal en ciertas áreas de los EF fueron los parques nacionales. Si bien en su creación se vislumbra el interés de ciertas élites por producir reservorios de belleza, en tanto elementos activos en la construcción de la nacionalidad (Zusman, 2008), también sirvieron para hacer efectiva la presencia estatal en regiones de reciente incorporación, pobladas por grupos indígenas.

En la práctica, los parques nacionales devinieron la principal referencia del Estado, llegando a ser "Estados-parque" (Navarro, 2008). Esto fue particularmente importante en el extremo sur del continente, en la región patagónica, distribuida entre la Argentina y Chile. La delimitación interestatal en esa región generó numerosas controversias, a la vez que la circulación entre ambos lados de la cordillera era fluida (Bandieri, 2005). A partir de la década de 1920 se crearon los parques nacionales de: Nahuel Huapi (1936), Lanín (1937) y Los Arrayanes (1971) del lado argentino; Vicente Pérez Rosales (1926); Villarica (1940) y Puyehue (1941) del chileno. Los parques nacionales se transformaron, virtualmente, en distritos fronterizos que ejercieron una función de "argentinización" y de "chilenización”, respectivamente (Valverde, 2012).

En la frontera de cada país, como parte de su mercado interior, se forman territorios productivos que no dependen estrictamente de la dinámica binacional. Un ejemplo lo ofrece la zona de Bermejo, ciudad boliviana ubicada en la frontera con Argentina: sus inmediaciones se transformaron, a partir de la década de 1970, en un centro de atracción para familias campesinas. Algunos colonizaron tierras vírgenes y otros ingresaron como 
obreros permanentes en empresas azucareras. Si las dos opciones anteriores fracasaban, participaban en el comercio como changarines (Jerez y Rabey, 2006). Esto garantizó la consolidación, allí, de un territorio azucarero para el mercado interno, superpuesto a otro comercial, orientado a compradores procedentes principalmente de la Argentina.

El trazado de límites, la presencia y persistencia de los Estados a uno y otro lado, va forjando identidades de un nosotros que busca diferenciarse del otro vecino. A escala local, las identidades culturales y sus adscripciones a dos nacionalidades yuxtapuestas en torno a un patrimonio que pudiera parecer compartido, merced la vecindad, se vuelve generador de fricciones. Un ejemplo de "territorialidad cultural" lo ofrece el carnaval en la conurbación binacional La Quiaca-Villazón, EF argentino-boliviano. Allí se produce una disputa entre agrupaciones carnestolendas de estas ciudades vecinas por la apropiación simbólica de "La diablada", una danza sincrética entre elementos prehispánicos y católicos que se realiza en las zonas de influencia aymara durante el carnaval, utilizando máscaras y trajes. Recrea la imagen del diablo y representa la lucha entre el bien y el mal.

La disputa por la apropiación simbólica de este festival se origina en la acción encarada por organizaciones bolivianas que buscan el reconocimiento de esa expresión cultural, por parte de la UNESCO, como patrimonio nacional.

El carnaval de Oruro se fue transformando en un evento global, similar al de Río de Janeiro. En 1984 esa ciudad se consagró "Capital Folklórica de Bolivia”, reconocimiento que posteriormente se le otorgó a Villazón — “Capital Folklórica del Sur"-, invistiéndola de un poder simbólico que sus habitantes quieren hacer valer. Las comparsas de La Quiaca, del lado argentino, fueron incorporando la estética y forma organizativa orureña. Para ello cruzaban a Villazón para alquilar trajes e instrumentos. Esta situación fue generando recelos, en la medida en que la salida de esos elementos desde Villazón hacia La Quiaca se veía como un despojo, lo que llevó a las autoridades locales, en ciertas ocasiones, a prohibir su alquiler a los residentes del país vecino (Karasik, 2000).

Involucrados directamente o no con los espacios fronterizos, se constituyen una diversidad de territorios de diferente tipo que se entraman en la construcción de estas entidades geohistóricas. 


\section{Territorios supranacionales}

Existe una infinidad de territorios supranacionales, de diferentes extensiones y naturaleza, que coexisten con los EF. Algunos abarcan toda la extensión de los países involucrados, como la Unión de Naciones Sudamericanas (Unasur), o el Mercosur. Estas organizaciones multilaterales son relevantes a la hora de pensar la dinámica fronteriza ya que, desde allí, por ejemplo, se están diseñando redes viales de escala continental (Unasur) o morigerando los efectos de los controles aduaneros sobre el comercio entre sus miembros (Mercosur). Otros territorios supranacionales se superponen sólo parcialmente con el espacio binacional, como aquellos creados para gestionar cuencas compartidas. Mediante acuerdos especiales se crearon agencias intergubernamentales con algún grado de autonomía para ocuparse de asuntos específicos en un área trasnacional. En el EF argentino-uruguayo se establecieron tres territorios de este tipo: la Comisión Administradora del Río Uruguay (CARU), la Comisión Administradora del Río de la Plata (CARP) y la Comisión Técnica Mixta del Frente Marítimo (CTMFM). También, se crearon este tipo de territorios binacionales para la gestión de represas hidroeléctricas en ríos compartidos: Salto Grande (Argentina-Uruguay), Itaipú (Brasil-Paraguay) y Yaciretá (Argentina-Paraguay), cada uno de los cuales tiene su propio organismo intergubernamental.

Pero no sólo los Estados nacionales impulsan territorios de esta escala con influencia directa en los EF; también las empresas. Un territorio económico supranacional es la Zona de Integración del Centro Oeste de América del Sur (Zicosur) surgida en 1997, que abarca sectores de todos los países de la región, excepto de Uruguay. Una de las principales actividades es la coordinación de agronegocios (Safarov, 2005). Otro tipo de territorios que atraviesan los EF son los promovidos por las comunidades indígenas. Un buen ejemplo es la "Manka Fiesta", o fiesta de las ollas, realizada en el mes de octubre en la ciudad argentina de La Quiaca. Es un evento sociocultural de raigambre indígeno-campesina. Los días que dura el evento se reúnen allí artesanos, agricultores y ganaderos, provenientes del norte argentino y el sur boliviano, para realizar intercambios comerciales y sociales (Campisi, 2001). Otro ejemplo es Aymaras Sin Fronteras, mencionado más arriba. 


\section{Lugares de frontera}

Si bien los Estados institucionalizaron sus distritos fronterizos como franjas adyacentes al límite internacional, es finalmente en ciertos sitios donde es rutinaria la convivencia con la sonoridad de la lengua hablada por el vecino del otro país, la circulación de camiones que llevan y traen mercaderías entre regiones metropolitanas o la presencia de las autoridades aduaneras. En estos sitios, el sentido de lugar está de alguna manera atravesado por su posición frontera y por la inmediatez del país vecino, que influye en la organización de los tiempos y los espacios cotidianos. Son los lugares de frontera, los más importantes de los cuales suelen ubicarse en las adyacencias de los pasos. Algunos sitios son preexistentes a los procesos de diferenciación territorial y de fronterización, como Concepción del

Figura 1. Lugares de frontera. Patrones de localización

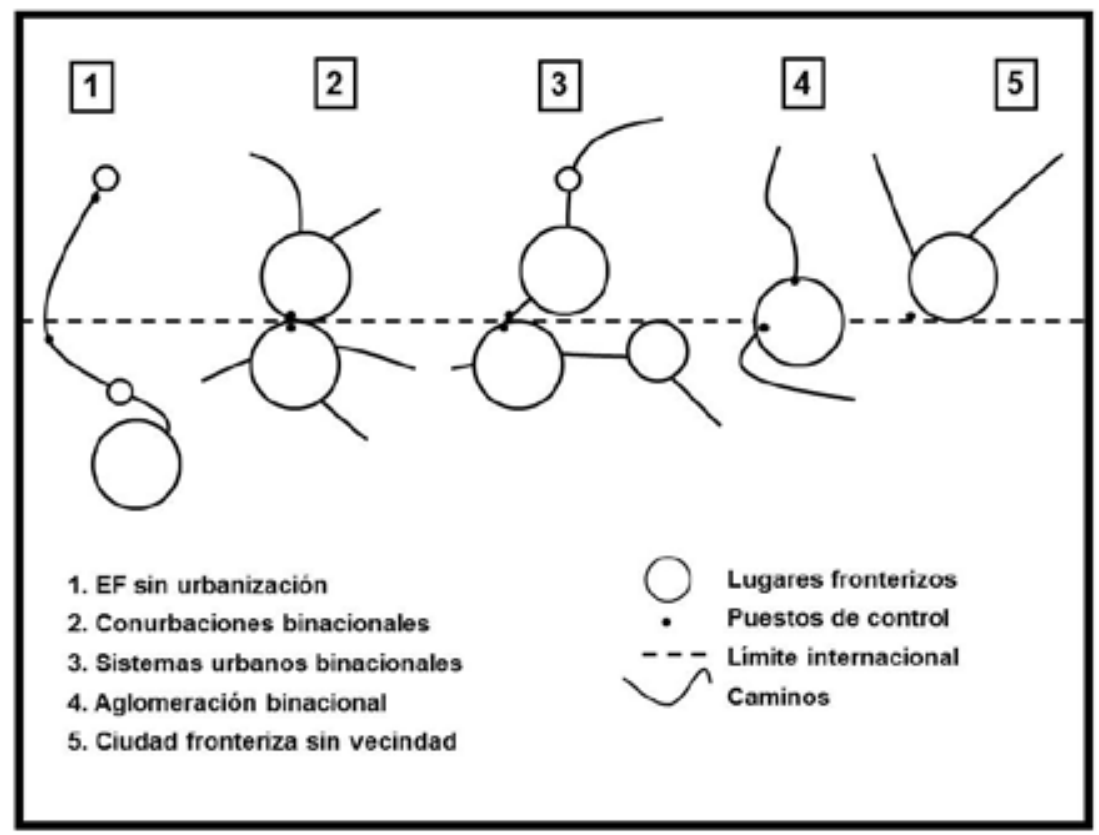

Fuente: Elaboración propia. 
Uruguay (Argentina), que funcionaba como puerto fluvial. La mayoría, empero, se originó por la superposición de marcas y caminos en tiempos republicanos. De todas formas, la ubicación sobre el límite no significa que el sentido de lugar esté marcado exclusivamente por la frontera. Esto dependerá de la pluralidad de funciones que concentre una ciudad, como Gualeguaychú (Argentina), por caso, cuya población se posicionó como lugar de frontera tras los reclamos locales realizados contra el establecimiento de fábricas pasteras del lado uruguayo, cortando el puente binacional. Pero también buscó convertirse como un lugar de atractivo turístico para habitantes de la región metropolitana de Buenos Aires, ligado a su ribera y a la realización del carnaval, además de ser un pequeño polo industrial. Lo fronterizo forma parte del entramado de sentidos que definen a este lugar. La mayor o menor intensidad de las movilidades fronterizas, la construcción de infraestructura de integración física, el desarrollo económico circunvecino y la relevancia geopolítica provocó un mayor o menor crecimiento de los lugares de frontera, contribuyendo a la configuración de los EF como realidades heterogéneas.

Si se considera la actual configuración material en los lugares de frontera se pueden identificar, al menos, cinco patrones, como se observó en la figura 1 .

1. Frontera sin urbanización. Muchos tramos de los EF se caracterizan por la dispersión de su población y por la ausencia de urbanizaciones y de procesos capitalistas de valorización de los recursos, a veces designada con la idea "frontera vacía". Tomando como referencia al trifinio entre Argentina, Bolivia y Chile en el Zapaleri, se advierte que no hay ninguna concentración importante de población en un radio de 100 kilómetros. La región, sin embargo, es intensamente transitada por grupos de pastores y llameros, muy móviles, de residencia dispersa, como ocurre en buena parte del espacio cordillerano. La mayor parte de los puestos de control en este EF trinacional concentra sólo al personal administrativo. El EF bolivianoparaguayo, de más reciente conformación, también se caracteriza por la ausencia de urbanizaciones. Para atravesarlo se construyó la ruta Transchaco en la década de 1960, pero la zona mantuvo un valor fundamentalmente militar. Recién cuando la mencionada ruta 
se pavimentó, tres décadas después, Bolivia y Paraguay incentivaron cierto proceso de fronterización en este sector del Chaco Boreal (Vázquez, 2009).

2. Conurbaciones binacionales. Los lugares de frontera arquetípicos son las llamadas "ciudades gemelas". Son pares de localidades contiguas al límite, en proceso de conurbación. El EF argentino-boliviano se organiza a partir de tres conurbaciones binacionales: La QuiacaVillazón, Aguas Blancas-Bermejo y Profesor Salvador Mazza-Yacuiba. Forman espacios construidos, discontinuados por un río diferente en cada caso, que han experimentado mayor crecimiento demográfico, urbanístico y comercial del lado boliviano, que se transformaron en apreciados destinos de compra para personas procedentes del norte argentino (Benedetti y Salizzi, 2011).

3. Sistemas urbanos binacionales. Surgen por la interacción entre localidades que no están contiguas al límite, no están enfrentadas, pero están conectadas, tal vez, más que con respecto a otras ciudades de los respectivos interiores. Un ejemplo interesante es, en el EF argentino uruguayo, el sistema Gualeguaychú-Fray Bentos-Mercedes-Dolores. Es un grupo de localidades interconectadas que, al menos todavía, no están en proceso de conurbación. El río Uruguay opera como barrera física que un puente construido en la década de 1970 le ha ido restando importancia.

4. Aglomeraciones binacionales. Las llamadas fronteras secas son aquellos EF formados a partir de un límite trazado en un terreno llano, sin ríos o relieves que sirvieran de base geofísica. La ausencia de discontinuidades físicas marcadas permite el desarrollo de manchas urbanas que se extienden libremente a ambos lados del límite. Es imposible, al menos en términos funcionales, distinguir dos ciudades. Es el patrón del EF brasileño-uruguayo. Allí se encuentran Chuí-Chuy, Rivera-Santana do Livramento y Aceguá-Aceguá, cada una formada a partir de una avenida cuya traza coincide con el límite internacional (Rodríguez, 2010).

5. Ciudades fronterizas. El fenómeno urbano de frontera no debería asociarse inevitablemente con continuidad a través del límite. Muchas ciudades limítrofes no cuentan con otra vecina, quedando en un cierto aislamiento dentro del EF. Esto se debe, generalmente, a razones de 
índole geofísica. Es el caso de Carmelo en la frontera uruguaya con la Argentina, enfrentada al Delta del Paraná, región poco habitada, o de Santa Helena, en la frontera brasileña con Paraguay, ubicada sobre el embalse de Itaipú.

\section{Movilidades}

Frontera y movilidad resultan indisociables. Las fronteras pueden pensarse como dispositivos creados por los Estados, localizados sobre los límites internacionales, para inmovilizar todo lo que ingresa/egresa desde el interior del territorio desde/hacia el vecino. La movilidad es una estrategia de encuentro, un tipo de relación que se establece entre uno y otro espacio. La continuidad se puede asociar a la movilidad, al facilitar la fluidez. La discontinuidad conlleva inmovilidad, fijeza. Pero las fronteras no deben verse sólo como una discontinuidad a las movilidades entre países linderos: también son destino y, además, áreas con movilidades internas o simples zonas de tránsito entre otros destinos interiores.

La movilidad espacial (en adelante sólo movilidad) es una relación social ligada al cambio de localización de personas y objetos entre lugares, en escalas espaciotemporales diversas (Levy, 2000). Los diferentes sujetos sociales se mueven y/o mueven objetos por la superficie terrestre como forma de reproducción social, para realizar intercambios, para controlar o apropiarse de un área, para sostener o crear vínculos con grupos distantes, para forjar identidades culturales. Las movilidades se expresan en una grandísima variedad de trayectorias espaciotemporales, donde se articulan transportes, infraestructuras y equipamientos. También son variados los conocimientos sobre los caminos, las razones para moverse, las exigencias y restricciones culturales, las posibilidades materiales de las personas para emprender un viaje (Gutiérrez, 2009) y los procesos asociados (Blanco, 2006), antes, durante y después del viaje.

Se propone a movilidad como una categoría genérica para referir todo aquello que está involucrado en las relaciones espaciales entre lugares, posible de ser concretada mediante el cambio de localización física de bienes y personas. Para la descripción de los EF se prestará atención a dos elementos: los caminos y las trayectorias. 
La superposición de territorios de diferentes niveles institucionales se traduce en una madeja de infraestructuras camineras con distintas capacidades de conexión. Los países sudamericanos han creado redes de transporte con diseños dendríticos a partir de las capitales-puerto, mientras que los esfuerzos por trazar rutas internacionales fueron limitados. En el caso del EF argentino-chileno sólo existió, hasta la década de 1990, para un límite internacional que supera los cinco mil kilómetros de longitud, un solo camino asfaltado en toda su extensión: el que conecta a Buenos Aires y Santiago. Se construyeron dos ferrocarriles trasandinos, uno paralelo al camino carretero recién mencionado y otro ubicado más al norte, que funcionó en forma limitada (Benedetti y Laguado, 2013).

Desde la década de 1990 el nuevo imperativo de la integración entre mercados nacionales impulsó la construcción de caminos para articular geografías nacionales mal conectadas, que en la década de 2000 derivó en el impulso a los ejes de integración de la IIRSA, modernizando algunas infra-

Figura 2. Relaciones entre caminos y espacios fronterizos

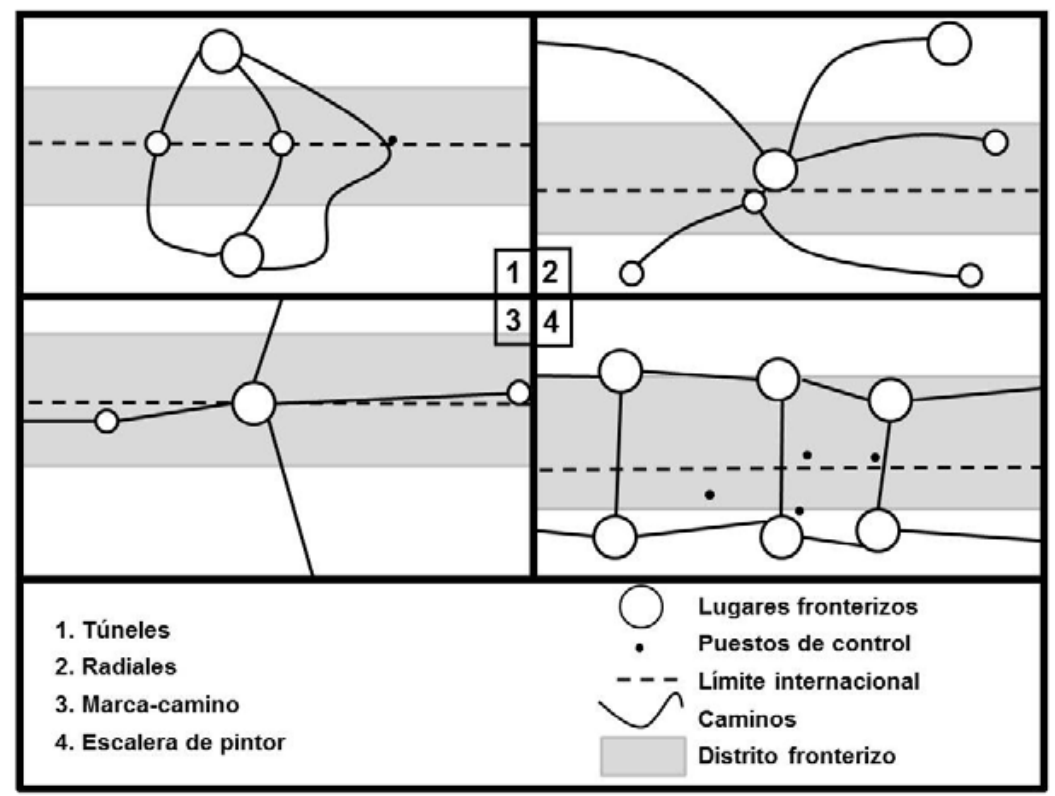

Fuente: Elaboración propia. 
estructuras existentes o construyendo nuevas. La mayoría de estos caminos son transversales a los límites internacionales, por lo que han acentuado las discontinuidades existentes a lo largo de los distritos fronterizos, entre tramos con caminos para todo tipo de vehículos y otros donde sólo son posibles las trayectorias con tracción a sangre. La excepción es el EF argentino-uruguayo, recorrido en toda su extensión por el eje de integración Chile-Mercosur. Es el corredor de transporte más importante de Sudamérica ya que conecta a Buenos Aires con San Pablo por Paso de los LibresUruguayana. Este punto de cruce registra el mayor tránsito comercial de Sudamérica (IIRSA, 2002). Las redes de caminos se complementan con otros subnacionales, de escala intermedia y municipal, además de caminos clandestinos realizados por actores vinculados a las movilidades ilegales.

Con el tiempo se fueron consolidando redes con diferentes diseños y capacidades de accesibilidad desde los interiores hacia el EF. En la relación entre EF y caminos se pueden reconocer, al menos, cuatro patrones, observables en la figura 2 .

1. Túnel. Los caminos atraviesan el EF, uniendo lugares alejados, generando un efecto túnel. Los lugares de frontera, en caso de formarse, son puntos intermedios en caminos que unen grandes distancias, una en cada país, manteniéndose en gran medida como puestos de control. No hay caminos importantes que faciliten la conectividad entre los lugares de frontera. Esto estaría denotando un EF poco atractivo para los territorios nacionales que lo conforman: es el caso argentino-boliviano, donde hay tres caminos que conectan a las ciudades bolivianas de Potosí y Tarija con las argentinas de Salta y Jujuy. En el intermedio se encuentran, sobre el límite y con una muy baja conectividad entre ellas, duplas de ciudades fronterizas donde se establecieron los controles y, con el tiempo, devinieron centros comerciales para ciudades de mayor tamaño. El EF tiende a ser zona de tránsito.

2. Radial. Este patrón surge cuando una gran ciudad se localiza en el EF, gravitando en el trazado de caminos, como en el caso argentinoparaguayo, donde se encuentra Asunción, capital del Paraguay, emplazada sobre el límite internacional. La región metropolitana de Asunción, con 2524719 habitantes, es el principal centro económico, 
político y cultural del Paraguay. Formando un sistema urbano binacional con esta ciudad, están Clorinda de 47004 habitantes (Argentina), Nanawa de 5457 habitantes (Paraguay) y otras pequeñas localidades más, hacia donde confluyen caminos desde las principales ciudades paraguayas y argentinas, además del Eje del Capricornio, que permite conexiones con el sur del Brasil y los puertos del norte de Chile.

3. Camino-marca. El camino principal se superpone en su traza con el límite, como ocurre en varios tramos del EF brasileño-uruguayo, donde la avenida que divide a las aglomeraciones binacionales sirve para unir a estas ciudades con otras también ubicadas sobre el límite.

4. Escalera de pintor. Hay dos caminos trazados perpendicularmente al límite, uno en cada país, algo equidistantes. Usando como imagen la escalera de pintor, esos caminos forman los largueros externos. Transversales, haciendo las veces de peldaños, se suceden diferentes caminos que cruzan el límite. Es el caso del EF argentino-chileno. Cada país trazó un camino paralelo al límite que recorre el territorio en toda su extensión de norte a sur, más alejado hacia el norte (a unos $200 \mathrm{~km}$ ) y menos hacia el sur (decenas de km). El límite está atravesado por 39 caminos, y en su intersección con la ruta vertical, han dado origen en sus inmediaciones a puntos urbanizados. Tres de esos caminos, además, han sido incorporados a la red de ejes de integración de la IIRSA. Este diseño, espejado, responde a un cierto esquema geoestratégico.

Pensar una trayectoria equivale a identificar los desplazamientos entre lugares y/o grupos de lugares, considerados como puntos de origen y destino, al menos temporarios, que realizan determinados grupos sociales, a través de los caminos, usando diferentes modos de transportes (incluyendo la tracción a sangre), recurrente, esporádica o excepcionalmente. Los lugares de frontera se vuelven atractivos por diferentes razones, algunas derivadas estrictamente de su posición en el borde del territorio (camiones que van hacia allí simplemente para cruzar hacia el otro país), otras por ser parte de una conurbación binacional donde la parte del país vecino se vuelve atractiva por algún motivo (normalmente por constituir un centro comercial) y, otras, por razones que van más allá de su posición 
fronteriza (lugar de atractivo turístico, polo industrial, capital de país o región). La multiplicidad de relaciones espaciales que establecen los lugares fronterizos son generadoras de una multiplicidad de trayectorias. Con el propósito de clasificarlas, teniendo en cuenta la experiencia del área que se está considerando, se pueden identificar al menos ocho tipos de trayectorias (figura 3). Para no extender el artículo no se ejemplificará (un antecedente de esta clasificación se presentó en Benedetti, 2011b).

1. Urbanas nacionales. Las ciudades de frontera tienen poblaciones que desarrollan allí mismo sus actividades rutinarias. Esto demanda una planificación local con independencia de los flujos internacionales y de las diferentes funciones que tienen las ciudades de frontera en la dinámica binacional. Son trayectorias que ocurren en el EF, en cada uno de sus lados.

2. Urbanas binacionales. Las duplas de lugares de frontera engendran distintas relaciones: de parentesco, religiosas o deportivas. Se generan trayectorias que ocurren en el EF, entre ambos lados.

Figura 3. Relaciones entre trayectorias de movilidad y espacios fronterizos

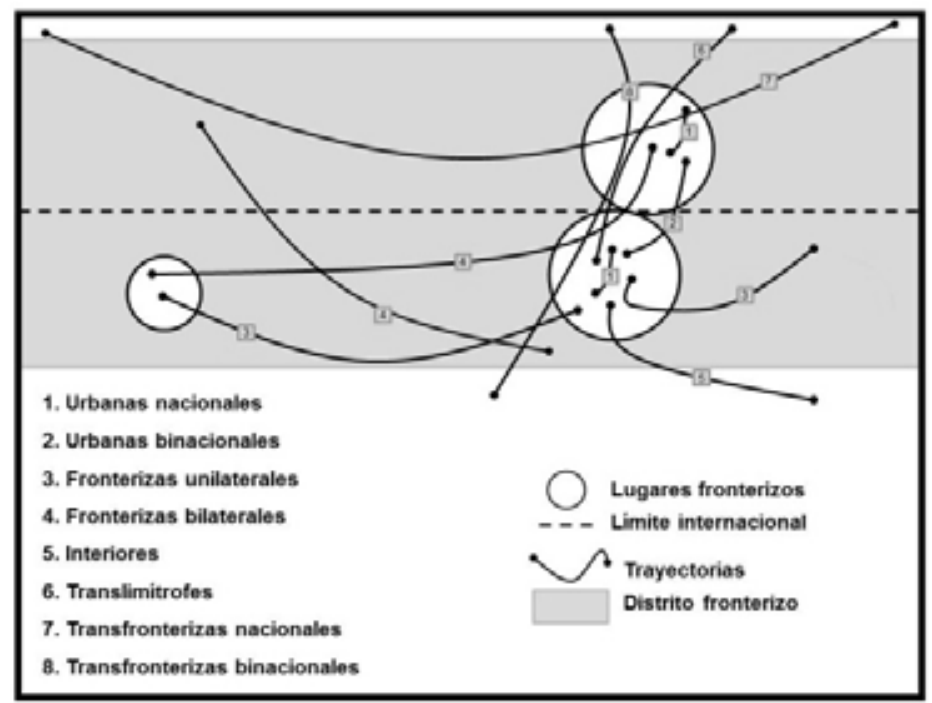

Fuente: Elaboración propia. 
3. Fronterizas unilaterales. Las ciudades de frontera pueden gravitar en las zonas circundantes del distrito fronterizo, para trámites diversos, motorizando trayectorias que ocurren en el EF, rural-urbanas o interurbanas, en cada uno de sus lados.

4. Fronterizas bilaterales. Son desplazamientos de uno a otro lado del EF. Puede deberse a territorialidades preexistentes al trazado del límite, que funcionan a partir de ciertas necesidades de recursos, como por ejemplo, el acceso a las pasturas para los pastores trashumantes. Son trayectorias que ocurren en el EF, entre ambos lados.

5. Interiores. Los puestos de control mantienen vínculos activos con las capitales nacionales. Este tipo refiere, pues, a las trayectorias entre la frontera y el interior del país: son desde/hasta este lado del EF.

6. Translimítrofes. Muchas ciudades de frontera, por ciertas asimetrías entre los países a los que pertenecen, se transforman en polos de atracción para los vecinos. Se generan trayectorias desde/hacia el interior de un país hasta el EF, allende el límite internacional, pero que no se internan en el país vecino. Por lo tanto, no son transfronterizas sino translimítrofes.

7. Transfronterizas nacionales. El EF es zona de tránsito entre lugares interiores de un país. Surgen trayectorias a través del ef, pero siempre de uno de sus lados.

8. Transfronterizas binacionales. Las relaciones espaciales más comúnmente estudiadas son las que generan trayectorias que van desde el interior de un país hacia el interior del otro país, atravesando todo el EF. Es lo que ocurre con el comercio de exportación e importación o con las migraciones. Son trayectorias a través del ef, desde el interior de un país hasta el interior del otro, cruzando el límite y ambas fronteras.

\section{Conclusiones}

Este artículo buscó presentar un modelo conceptual para estudiar los espacios fronterizos. Surgió del propio trabajo de recopilación y sistematización de material empírico sobre las fronteras construidas por los países del sur sudamericano. Los espacios fronterizos estudiados son aquellos que se estructuran en las zonas de yuxtaposición de territorios formados por los 
Estados nacionales de la región sur sudamericana, que abarca a la Argentina (de la cual se tiene mayor cantidad de evidencia empírica), Bolivia, Brasil, Chile, Paraguay y Uruguay.

Como se insistió, un espacio fronterizo está conformado por tres elementos básicos: el límite internacional establecido entre dos Estados soberanos y las fronteras que cada uno de esos países construyó, cada uno a su tiempo, junto a ese límite. El resultado es una díada. Sin embargo, sería incorrecto sostener que el espacio fronterizo surge solamente por la acción de dos Estados, como si fueran entidades monolíticas que concentran el poder. Desde una mirada multiescalar, se puede afirmar que los límites y las fronteras formados por los Estados son una de las escalas constitutivas del espacio fronterizo, en algunos casos el más importante (especialmente en las zonas de mayor tránsito entre los países linderos) y en otros el menos importante (como ocurre en algunas zonas con movilidades escasas y dispersas). En todos los casos, no se debe perder de vista que el moderno Estado-nacional es la entidad que generó esa forma particular de espacialidad que, por la cantidad de elementos materiales y simbólicos que fue concentrando, se fue diferenciando notablemente de otras fronteras, como la agropecuaria, la de conquista militar o la urbano/rural. Estos últimos arquetipos de frontera, asimismo, han concitado un menor interés conceptual de parte de la geografía contemporánea.

Para ordenar la lectura de los espacios fronterizos, con base en un exhaustivo trabajo empírico que todavía se está llevando a cabo, se identificaron, caracterizaron y ejemplificaron seis componentes básicos. Mediante este modelo conceptual se procuró ordenar el entendimiento de los espacios fronterizos y comenzar a dar respuesta a una pregunta básica: ¿cómo son las fronteras sudamericanas? La respuesta a esta pregunta será progresivamente respondida según avance la recopilación y sistematización, ahora según el modelo aquí presentado, de una mayor cantidad de evidencias empíricas.

\section{Bibliografía}

Anderson, B. (1991). Imagine communities. Reflexions on the origin and spread of nationalism [Comunidades imaginadas]. México: Fondo de Cultura Económica. 
Ansaldi, W. y Giordano, V. (2012). Presupuestos teórico-metodológicos para el análisis socio-histórico del proceso de formación de los Estados latinoamericanos. Revista Estudios del ISHiR, (4), 42-81.

Bandieri, S. (2005). Historia de la Patagonia. Buenos Aires: Sudamericana.

Benedetti, A. (2005). La Puna de Atacama como construcción geopolítica. Transformaciones territoriales posteriores a la Guerra del Pacífico (1889-1900). Revista Si Somos Americanos, VII(2), 155-183.

Benedetti, A. (2007). El debate sobre las fronteras en la Argentina. Revista Estudios Socioterritoriales, $\operatorname{VI}(6), 11-36$.

Benedetti, A. (2009). Los usos de la categoría región en el pensamiento geográfico argentino. Scripta Nova, XII(286). Recuperado de Universidad de Barcelona: $<$ http:www.ub.es/geoscrit/sn/sn-286.htm>.

Benedetti, A. (2011a). Territorio: Concepto integrador de la geografía contemporánea. En P. Souto (Coord.), Territorio, lugar, paisaje. Prácticas y conceptos básicos en geografía (pp. 11-82). Buenos Aires: Facultad de Filosofía y Letras, Universidad de Buenos Aires.

Benedetti, A. (2011b). Lugares de frontera y movilidades comerciales en el sur sudamericano. Una aproximación multiescalar. En E. A. Costa, G. V. L. Costa y M. A. M. Oliveira, Fronteiras em foco (pp. 33-55). Campo Grande: Editora da UFMS.

Benedetti, A. y Salizzi, E. (2011). Llegar, pasar, regresar a la frontera. Aproximación al sistema de movilidad argentino-boliviano. Revista Transporte y Territorio, (4), 148-179.

Benedetti, A. y Laguado, I. (2013). El espacio fronterizo argentino-chileno. Definición de categorías operativas y primera aproximación descriptiva. En A. Núñez, F. Arenas y R. Sánchez (Eds.), Fronteras, territorios y montañas. La cordillera de los Andes como espacio cultural (pp. 451-483). Santiago de Chile: Instituto de Geografía, Pontificia Universidad Católica de Chile.

Blanco, J. (2006). De la noción de impacto a la de procesos asociados. Reflexiones a partir de la relación autopistas-urbanización en la región metropolitana de Buenos Aires. Revista Mundo Urbano, (28).

Brovetto, C. (2010). Educación bilingüe de frontera y políticas lingüísticas en Uruguay. Pro-Posições, 21, 3 (63), 25-43.

Campisi, A. (2001). La "Manka Fiesta”, La Quiaca. La construcción social de un espacio de intercambio. Breves contribuciones del IEG, (12), 21-49.

Cataia, M. (2007). A relevância das fronteiras no período atual: unificação técnica e compartimentação política dos territórios. Scripta Nova, XI(245), (21).

Cicalese, G. (2009). Geografía, guerra y nacionalismo. La Sociedad Argentina de Estudios Geográficos (GAEA) en las encrucijadas patrióticas del gobierno militar, 1976-1983. Scripta Nova, XIII(308). Recuperado de < http://www.ub.es/ geocrit/sn/sn-308.htm >. 
Lopes de Souza, M. (1995). O território: Sobre espaço e poder, autonomia e desenvolvimento. En I. E. de Castro, P. C. da Costa G. y R. Lobato C. (Org.), Geografia: Conceitos e temas. Río de Janeiro: Bertrand.

Domínguez, J. (2003). Conflictos territoriales y limítrofes en América Latina y el Caribe. En J. Domínguez (Comp.), Conflictos territoriales y democracia en América Latina. Buenos Aires: Universidad de Belgrano-flacso, Siglo Xxi.

Ferrero, M. (2006). La globalización en acción: Regionalismo y paradiplomacia en Argentina y el Cono Sur latinoamericano. Revista Electrónica de Estudios Internacionales, (11), 1-26. Recuperado de < http://www.reei.org/reei\%2011/ reeil1.htm $>$.

Foucher, M. (1988). Fronts et frontières. Un tour du monde géopolitique. París: Fayard. García Á., J. (2002). Provincias, regiones y comunidades autónomas. La formación del mapa político de España. Madrid: Temas del Senado, Secretaría General del Senado, Dirección de Estudios y Documentación, Departamento de Publicaciones.

González M., S. (2009). El Norte Grande de Chile y sus dos triple-fronteras: Andina (Perú, Bolivia y Chile) y circumpuneña (Bolivia, Argentina y Chile). Cuadernos Interculturales, 7(13), 27-42.

Grimson, A. (2003). La nación en sus límites. Contrabandistas y exiliados en la frontera Argentina-Brasil. Buenos Aires: Gedisa.

Gutiérrez, A. (2009). Movilidad o inmovilidad: ¿Qué es la movilidad? Aprendiendo a delimitar los deseos. Buenos Aires: xv CLATPU.

Haesbaert, R. (2004). O mito da desterritorialização: Do "fim dos territórios" à multiterritorialidade. Río de Janeiro: Bertrand Brasil.

Hobsbawm, E. (1990). Naciones y nacionalismos desde 1780. Buenos Aires: Crítica.

Iniciativa para la Integración Regional Suramericana (IIRSA). (2002). Facilitación del transporte en los pasos de frontera. Recuperado de < http://www.iirsa.org/ BancoMedios/Documentos\%20PDF/pfd_ftpf_completo.pdf $>$.

Jerez, O. y Rabey, M. (2006). Ciudades de frontera e industria azucarera. Cuaderno Urbano, (5), 7-34.

Karasik, G. (2000). Tras la genealogía del diablo. Discusiones sobre la nación y el Estado en la frontera argentino-boliviana. En A. Grimson (Comp.), Fronteras, naciones e identidades. La periferia como centro. Buenos Aires: Ediciones CiccusLa Crujía.

Kralich, S., Benedetti, A. y Salizzi, E. (2012). Aglomeraciones transfronterizas y movilidad. Una aproximación desde casos sudamericanos. Boletim Gaúcho de Geografia, 38.

Lacoste, P. (Ed.). (2004). Argentina, Chile y sus vecinos (1810-2000). Córdoba: Caviar Bleu.

Levy, J. (2000). Les Nouveaux Espaces de la Mobilité. En M. Bonnet y D. Desjeux. Les territoires de la mobilité. París: Presses Universitaires de France. 
Lladó M., B. (2005). Discurs, história i poder: Lectures geográphique de Michel Foucault. Documentos de Análisis Geográfica, (46), 151-160.

Machado, L. O. (1990). O significado e configuração de uma fronteira urbana na Amazônia. En B. Becker, M. Miranda y L. Machado. Fronteira amazônica: Questões sobre a gestão do território. Brasil: UnB.

Navarro F., P. (2008). El proceso de construcción social de la región del Nahuel Huapi en la práctica simbólica y material de Exequiel Bustillo (1934-1944). Revista Pilquen, (9), 1-14.

Newman, D. y Paasi, A. (1998). Fences and neighbours in the postmodern world: Boundary narratives in political geography. Progress in Human Geography, 22(2), 186-207.

Paasi, A. (1986). The institutionalization of regions: A theoretical framework for understanding the emergence of regions and the constitution of regional identity. Fennia, 164(1), 105-146.

Paasi, A. (2003). Territory. En J. Agnew, K. Mitchell y G. Toal (Eds.), A companion to political geography. Oxford: Blackwell Publishers.

Paasi, A. (2013). Borders. En Klaus Dodds, K. Merje y J. Sharp (Eds.), The Ashgate research companion to critical geopolitics. Londres: Ashgate.

Quintero, S. (1999). El país que nos contaron. La visión de Argentina en los manuales de geografía (1950-1997). Entrepasados, (16), 135-154.

Quintero, S. (2007). Territorio, gobierno y gestión. Temas y conceptos de la nueva geografía política. En V. F. Caso y R. Gurevich (Coords.), Discursos y prácticas en la enseñanza de la geografía. Buenos Aires: Biblos.

Raffestin, C. (1980). Pour une géographie du pouvoir. [Por uma geografia do poder]. São Paulo: Atica.

Rapoport, M. (1998). Os países do Cone Sul e as grandes potências. En A. L. Cervo y M. Rapoport (Orgs.), História do Cone Sul. Río de Janeiro: Editora Revan y Editoria Universidade de Brasília.

Ratzel, F. (1897). Politik Geografie. [Géographie politique]. París: Económica.

Rey B., R. (1979). Limites y fronteras de la República Argentina. Epitome geográfico. Buenos Aires: orkos.

Rodríguez M., A. (2010). La frontera Uruguay-Brasil y el desarrollo local. Nóesis. Revista de Ciencias Sociales y Humanidades, 19(37), 14-51.

Rouvière, L. (2009). ¿Un territorio político transfronterizo? Formas de legitimación de una experiencia de acción política intermunicipal entre Bolivia, Chile y Perú (вср). Si Somos Americanos. Revista de Estudios Tranfronterizos, IX(2), 1329.

Sack, R. (1986). Human territoriality. Its theory and history. Cambridge: Cambridge University Press.

Safarov, A. (2005). La Zona de Integración del Centro Oeste de América del Sur (Zicosur) como puente para las relaciones entre Latino-América y Corea del 
Sur. En E. Oviedo (Comp.). Corea... una mirada desde Argentina. Rosario: UNR Editora.

Santos, M. (1996). A Natureza do espaço. São Pablo: Hucitec.

Valverde, S. (2012). Do deserto á fronteira: Conformação do estado-nação: Pioneiros, povoadores e indígenas na Patagônia setentrional, Argentina. En H. Trinchero y T. Oliveira (Orgs.), Fronteiras platinas. Território e sociedade. HDourados: UFGD.

Vázquez, F. (2009). El Chaco como frontera total en Paraguay: Del aislamiento a la integración transfronteriza. En E. Aparecido da Costa y M. A. Machado de Oliveira (Orgs.), Seminário de Estudos Fronteiriços. Campo Grande: Editora UFMS.

Zusman, P. (2008). El paisaje: La razón y la emoción al servicio de la práctica turística. En R. Bertoncello (Comp.). Turismo y geografía. Lugares y patrimonio natural-cultural de la Argentina. Buenos Aires: Ediciones Ciccus. 